\title{
Uterus transplant: Are we close to this reality?
}

\section{TRANSPLANTE UTERINO: ESTAMOS PERTO DESTA REALIDADE?}

\author{
Dani Ejzenberg ${ }^{1}$, José Maria Soares Júnior ${ }^{1}$, Edmund C. Baracat ${ }^{1}$ \\ ${ }^{1}$ Division of Gynecology, Department of Obstetrics and Gynecology, Hospital das Clínicas, Faculdade de Medicina, Universidade de São Paulo (FMUSP), São Paulo, SP, Brazil \\ http://dx.doi.org/10.1590/1806-9282.62.04.295
}

Some cases of infertile couples are such insuperable challenges that they become dramatic, especially when women cannot become pregnant due to a congenitally absent uterus (Mayer Rokitansky Küster Hauser - MRKH syndrome), or because it has been removed unexpectedly before childbearing. This may occur after hysterectomy for treatment of cervical or endometrial cancer, uterine leiomyoma, or postpartum hemorrhage. ${ }^{1}$

It is estimated that the uterine factor represents 3 to $5 \%$ of cases of infertility. ${ }^{1}$ This abnormality may have great impact on the psychic sphere of many women, because the options that remain are adoption or use of a replacement uterus. Both alternatives present difficulties. In the first case, the slowness and bureaucracy involved, while the second includes the need for a relative or friend willing to risk a pregnancy and the emotional ties that could develop in relation to this baby. Moreover, the latter option is not allowed in many countries such as Japan and Sweden. Then, the only option left for patients who want to use their gametes is the possibility of uterine transplant, ${ }^{2}$ even if experimental.

Early research using animal models for uterus transplant occurred in the 1960s and 1970s. It involved dogs, sheep and primates. The initial idea was to transplant the uterus along with the fallopian tubes to solve tubal factor infertility. ${ }^{3}$ In the first experiments, two main issues were raised: How to provide appropriate vascular support to the transplanted organ; and how to prevent rejection with the use of non-teratogenic substances. These challenges were not fully resolved at the time and are still concerns of researchers. ${ }^{4,5}$ The advent of in vitro fertilization, which was successful in humans at the end of the 1970s, reduced massively interest in uterus transplantation research in animal models such as mice, ${ }^{6}$ rats, ${ }^{7}$ rabbits, ${ }^{8}$ sheep ${ }^{9}$ and monkeys ${ }^{10}$ for many years. However, it did not solve the problem of women with MRKH.

In 2000, the first uterine transplant in women was carried out when a patient, who had lost her womb giving birth, received the uterus of a living donor in Saudi Arabia. However, this case progressed to graft loss and hysterectomy after three months of transplantation. ${ }^{11}$ This created frustration at that time and many researchers were skeptical about the success of the uterus transplants.

The second transplant was performed in 2011 in Turkey, with a report of two pregnancies in the transplanted uterus, even though both ended in abortion. ${ }^{12}$ More recently, in 2014, the first birth of a series of nine patients undergoing uterine transplantation occurred in Sweden. ${ }^{13}$ Some researchers believe that this event was a milestone in reproductive medicine, allowing pregnancy in a woman aged 35 years with congenital uterine agenesis (MRKH syndrome) who received the uterus from a 61-year-old donor that became menopausal seven years earlier. ${ }^{13}$ Subsequently, three more births were successfully described, and others may result from this series of cases. ${ }^{14-16}$ Therefore, a new frontier is opening up with these reports in the field of human reproduction. ${ }^{14}$

Uterus transplant, even with the very small number of successful cases to date, is a major breakthrough in reproductive medicine enabling pregnancy in women who did not have a uterus. It is noted that the development of this technique was possible only after great efforts in the field of microsurgical techniques; extensive training in animal models; research developed with transplantation of other organs; and advances in human reproduction, such as embryo cryopreservation and embryo biopsy; as well as the enhancement of drugs to prevent rejection of the uterus. ${ }^{13-19}$

The evolution of immunosuppressants greatly diminished the fear of teratogenicity and raised the expectation of success, especially after the reports of the Swedish group. ${ }^{13}$ However, training in other centers is necessary both regarding the technical aspect of transplants and management of immunosuppressive therapy. ${ }^{18,19}$

We all know that there are still major challenges for the improvement of the technique, selection of potential donors, and the preservation of the organ to be transplanted. Another highlight of this therapeutic modality ${ }^{20}$ will be containing the expectation of success within the community in face of a learning curve required to implement any procedure. Finally, uterus transplant can be considered as a therapeutic hope for women who were born without a uterus or lost it unexpectedly during their reproductive life. 


\section{REFERENCES}

1. Milliez J. Uterine transplantation FIGO Committee for the Ethical Aspects of Human Reproduction and Women's Health. Int J Gynaecol Obstet. 2009; 106(3):270.

2. Kisu I, Banno K, Mihara M, Suganuma N, Aoki D. Current status of uterus transplantation in primates and issues for clinical application. Fertil Steril. 2013; 100(1):280-94.

3. Brännström M, Wranning CA, Marcickiewicz J, Enskog A, Hanafy A. Uterus transplantation - substantial progress in research but not yet ready for the clinic. Middle East Fertility Society Journal. 2007; 12(2):86-95.

4. Barzilai A, Paldi E, Gal D, Hampel N. Autotransplantation of the uterus and ovaries in dogs. Isr J Med Sci. 1973; 9(1):49-52.

5. O'Leary JA, Feldman M, Gaensslen DM. Uterine and tubal transplantation. Fertil Steril. 1969; 20(5):757-60.

6. Racho El-Akouri R, Kurlberg G, Dindelegan G, Mölne J, Wallin A, Brännström M. Heterotopic uterine transplantation by vascular anastomosis in the mouse. J Endocrinol. 2002; 174(2):157-66.

7. Lee S, Mao L, Wang Y, D'Silva M, Yoo CH, Wolf P, et al. Transplantation of reproductive organs. Microsurgery. 1995; 16(4):191-8.

8. Confino E, Vermesh M, Thomas W, Gleicher N. Non-vascular transplantation of the rabbit uterus. Int J Gynaecol Obstet. 1986; 24(4):321-5.

9. Zhordania IF, Gotsiridze OA. Vital activity of the excised uterus and its appendages after their autotransplantation into omentum. Experimental research. Acta Chir Plast. 1964; 6:23-32.

10. Scott JR, Pitkin RM, Yannone ME. Transplantation of the primate uterus. Surg Gynecol Obstet. 1971; 133(3):414-8.

11. Fageeh W, Raffa H, Jabbad H, Marzouki A. Transplantation of the human uterus. Int J Gynaecol Obstet. 2002; 76(3):245-51.
12. Erman Akar M, Ozkan O, Aydinuraz B, Dirican K, Cincik M, Mendilcioglu I, et al. Clinical pregnancy after uterus transplantation. Fertil Steril. 2013; 100(5):1358-63

13. Brännström M, Johannesson L, Bokström H, Kvarnström N, Mölne J, DahmKähler P, et al. Livebirth after uterus transplantation. Lancet. 2015; 385(9968):607-16.

14. Bagnoli VR, Fonseca AM, Fassolas G, Arie MHA, Arie WMY, Baracat EC. Conduta frente às malformacões genitais uterinas: revisão baseada em evidências. Femina. 2010; 38(4):217-28.

15. Brännström M, Johannesson L, Dahm-Kähler P, Enskog A, Mölne J, Kvarnström N, et al. First clinical uterus transplantation trial: a six-month report. Fertil Steril. 2014; 101(5):1228-36.

16. Brännström M, Diaz-Garcia C, Hanafy A, Olausson M, Tzakis A. Uterus transplantation: animal research and human possibilities. Fertil Steril. 2012; 97(6):1269-76.

17. Østensen M, Khamashta M, Lockshin M, Parke A, Brucato A, Carp H, et al. Anti-inflammatory and immunosuppressive drugs and reproduction. Arthritis Res Ther. 2006; 8(3):209.

18. Blume C, Pischke S, von Versen-Höynck F, Günter HH, Gross MM Pregnancies in liver and kidney transplant recipients: a review of the current literature and recommendation. Best Pract Res Clin Obstet Gynaecol. 2014; 28(8):1123-36.

19. Johannesson L, Kvarnström N, Mölne J, Dahm-Kähler P, Enskog A, DiazGarcia C, et al. Uterus transplantation trial: 1-year outcome. Fertil Steril. 2015; 103(1):199-204

20. Damous LL, Nakamuta JS, de Carvalho AE, Soares-Jr JM, de Jesus Simões $\mathrm{M}$, Krieger JE et al. Adipose tissue-derived stem cell therapy in rat cryopreserved ovarian grafts. Stem Cell Res Ther. 2015; 6:57. 